\title{
The ECHA Board of Appeal - A Look at Issues that will Shape its Future
}

\author{
Andrew Fasey *
}

After almost 8 years and over a hundred decisions on appeals it is safe to say that being a member of the European Chemicals Agency (ECHA) Board of Appeal (BoA) has not been easy. Being the technically qualified member (TQM) of the ECHA BoA has proved to be challenging and interesting in equal measure. The cases almost invariably raise new and often complex legal and scientific issues and always challenge the members of the BoA to think things through from first legal principles through to understanding complex scientific ideas. And it is this that makes the job of technically qualified member of the ECHA BoA one of the most rewarding imaginable. Constantly balancing legal principles with regulatory demands with the uncertainty of science; balancing three things and perhaps more is never going to be easy.

Throughout its existence, the BoA has strived to demonstrate its impartiality and independence. In the end you will not take my word for this but will need to be convinced by the quality, and sound and robust nature of our decisions. I hope that we have done enough to persuade you.

In this edition of ICRL there are two contributions on the work of the BoA. I should stress that I have, at no stage, provided input on these contributions and their content as this would not only raise into question my impartiality but also ICRL's. I do, however, welcome any reasoned and thorough assessment of our work and I believe the BoA and its decisions are certainly worthy of such attention. Like any organisation we can always do better and experts in the field shining a light on what we do and how well we are doing it can only be helpful. I look forward to other articles and research on the work of the BoA in the future.

I feel confident in saying that the ECHA BoA has established itself in the REACH firmament and as part of the EU legal and regulatory structure. However, interesting times lie ahead. The BoA is seen by some as an expensive luxury but one that is welcomed by stakeholders and is seen as a necessary part of the REACH (and BPR) system. Will this view be maintained as the work of ECHA changes over time (for example, the registration deadlines have passed and SIEFs are no more)? Will the European institutions and the EU Member States want to maintain the BoA in its current form? Will the tasks of the BoA change as other legislation or regulatory tasks pass to ECHA? The relationship between the BoA and the ECHA Secretariat has been a constant challenge but

* Andrew Fasey is a Technically Qualified Member of the ECHA Board of Appeal and a member of the ICRL Editorial Board. For Correspondence: <Andrew.FASEY@echa.europa.eu>. 
ECHA now has a new Executive Director (ED). Will this sometimes 'frosty' relationship thaw? Or perhaps it is better if there is a degree of 'creative tension' between the BoA and ECHA? How will the new ED interpret the work of BoA? Will ECHA implement BoA decisions in a different way to the previous regime? Next year (2019) the BoA will have a new Chair. Mercedes Ortuno, the outgoing Chair, has worked tirelessly to protect the BoA, to ensure that it is seen as being independent and to convince stakeholders that a BoA has a real value mainly through the quality of its decisions. Will a new Chair have a similar approach? Will they be as effective? Will resources impact on how the BoA does it's work? And then there is Brexit. I am British so how will I be affected? Will I be able to see through my mandate? What will the attitude be of Member States and stakeholders to a British person in a decision-making position post-Brexit? And what if there is a hard Brexit? This is just a flavour of the changing and challenging environment that the ECHA BoA will be operating in over the coming years.

The ECHA BoA has produced an extensive body of robust and sound decisions giving clarity to many of the more complex and, perhaps, 'grey' areas of the REACH Regulation. It has made decisions that ensure that REACH (in particular) is interpreted and implemented as set-out in the legislation. However, no one should make assumptions about the future. It is a vulnerable body with very limited resources compared to those available to the ECHA Secretariat. If stakeholders want an effective BoA they must keep their eye on the ball and ensure that the BoA is protected and nurtured. After all, something gained can easily be lost. 